\section{FOREST CARBON}

\section{Forest disturbance}

Glob. Change Biol. http://doi.org/s6x (2014)

It is clear that deforestation leads to the release of carbon stored in tropical forests and a great deal of work has been done to estimate how much carbon is emitted as a result. The carbon implications of forest degradation from human disturbances, such as selective logging, understorey fires and forest fragmentation, remain less well quantified.

Erika Berenguer from Lancaster University, UK, and co-workers undertook the largest field study of its kind so far to begin to address this knowledge gap. They were particularly interested in understanding the combined effects of different forms of forest disturbance on the major carbon pools (aboveground, dead wood, litter and soil carbon) in tropical forests.

They found that live vegetation - the largest pool - was the most sensitive to disturbance, with affected areas containing on average $40 \%$ less aboveground carbon than undisturbed forests. Conversely soil stocks seemed to be resistant to disturbance, and the dead wood and litter carbon pools displayed rapid recovery potential. Extrapolating their findings using records of the annual forest disturbance area in the Brazilian Amazon indicates that the carbon loss from forest degradation could release $40 \%$ more carbon than deforestation alone.

\section{PSYCHOLOGY}

\section{Geoengineering views}

Climatic Change http://doi.org/s6z (2014)

Descriptions of new technologies, including geoengineering, can influence the way the public perceive them. Previous studies have analysed geoengineering reporting in news articles, but little experimental investigation about the effect of different frames on public views has been carried out so far.

Adam Corner and Nick Pidgeon of Cardiff University, UK, have filled this gap with an online experiment, using 412 UK participants recruited during early 2013. Participants read a different description of geoengineering. In the experimental condition, the description was 'framed' using an analogy to natural processes (for example the release of millions of small particles that reflect sunlight into the highest part of the atmosphere was compared with the cooling effect of a volcanic eruption). In a control condition a more standard description was used. The results show that participants in the experimental condition were more likely to support geoengineering as a solution to climate change.

The researchers advise using caution when communicating geoengineering with natural analogies as it can lead to an unjustified favourable perception about the technologies.

$M C$

\section{OCEANOGRAPHY}

\section{Polar response asymmetry Phil. Trans. R. Soc. A 373, 20130040 (2014)}

Climate change is having different temperature impacts on the two polar regions. While the Arctic is warming at a greater rate than elsewhere, the Antarctic has predominantly experienced cooling and sea-ice expansion. John Marshall, of Massachusetts Institute of Technology, USA, and colleagues investigated this phenomenon by considering the role the ocean may play.

The authors consider how differences in ocean circulation - with surface waters sinking to depth in the high-latitude North Atlantic compared with upwelling of deep
MITIGATION

\section{Water costs of afforestation}

Agric. Forest Meteorol. 195-196, 32-37 (2014)

Afforestation is one way to sequester carbon dioxide from the atmosphere and mitigate climate change, but choosing the best location is not always straightforward.

Yang Gao from the Institute of Geographic Sciences and Natural Resources Research, China, and colleagues investigated the water consumption cost of carbon sequestration (WCCC) for afforestation projects in China. They find an abrupt change in ecosystem and plant water-use efficiency coincident with the 400-500 $\mathrm{mm}$ average annual precipitation isopleth, where the WCCC is $1 \mathrm{~kg} \mathrm{H}_{2} \mathrm{O}$ per g C. This threshold represents a boundary beyond which afforestation may lead to land degradation due to water depletion.

Unfortunately China's major afforestation programmes are mostly concentrated in relatively arid areas with a high WCCC to the west of the $400-500 \mathrm{~mm}$ precipitation isopleth. This illustrates the importance of considering water-use efficiency when selecting sites for afforestation. waters around Antarctica - influence the response of sea surface temperatures, and therefore atmospheric temperature, to greenhouse gas and other forcings. Although the two regions are subjected to similar greenhouse gas forcing, the Antarctic is also experiencing ozone depletion.

They conclude that at present the cooling of the Antarctic is associated with effects related to ozone depletion in the region, which is cancelling the warming due to greenhouse gases. They suggest that this is a short-term effect, as ozone recovers and adds to the warming. In contrast, the Arctic is experiencing warming that is enhanced by ocean heat transport and this is expected to continue.

\section{WATER RESOURCES}

\section{Shifting El Niño takes rains}

Geophys. Res. Lett. http://doi.org/s62 (2014)

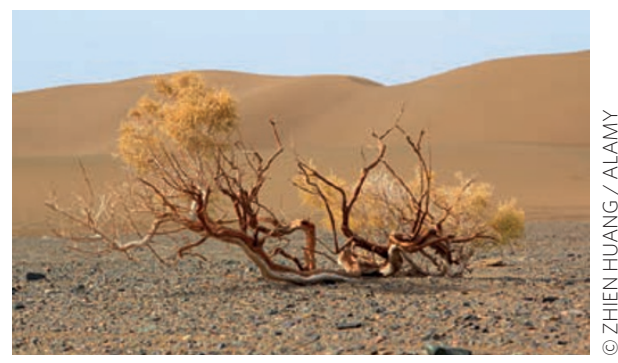

Southern China has experienced more frequent autumn droughts during the past two decades. Observations show that precipitation has been greatly reduced since 1990, during this season of transition from the wet summer monsoon to the dry winter months.

Wenjun Zhang, of Nanjing University of Information Science and Technology, China, and co-workers studied the causes behind this precipitation shift using observations of rainfall, sea surface temperature and atmospheric circulation. They found that there has been an increase in central Pacific El Niño events - where the sea surface temperature anomaly is found in the central Pacific, compared with the more traditional, or eastern Pacific, location.

This shift in the El Niño location influences precipitation over Southern China, with very low precipitation during central Pacific events and excess precipitation during eastern Pacific events. As global warming may cause an increase in central Pacific El Niño events, this could have serious water resource implications for the region.

Written by Alastair Brown, Monica Contestabile and Bronwyn Wake. 